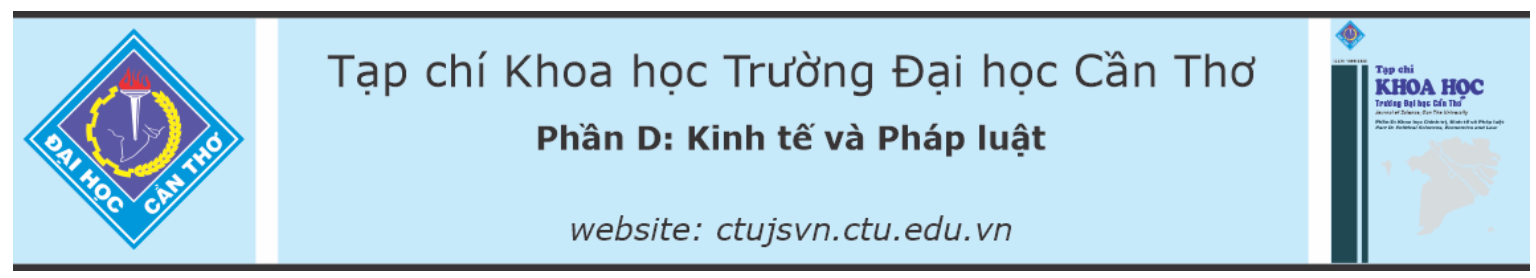

DOI:10.22144/ctu.jvn.2021.193

\title{
ĐỘNG LỰC CÁ NHÂN, Ý ĐỊNH CHIA SẺ TRI THÚC VẢ PHÁT TRIỂN SẢN PHẨM MỚI TRONG NGÀNH DU LICH
}

\author{
Đoàn Bảo Sơn* \\ Hoc viện Hàng không Việt Nam \\ *Nguoòi chịu trách nhiệm chính về bài viết: Đoàn Bảo Sonn (email: sondb@vaa.edu.vn)
}

\section{Thông tin chung:}

Ngày nhận bài: 02/06/2021

Ngày nhận bài sủa: 10/07/2021

Ngày duyệt đăng: 25/12/2021

Title:

Individual motivations, knowledge sharing and new product development in the tourism industry

\section{Tù khóa:}

Du lịch, niềm vui, phần thuơơng, sản phấm mới, sụ có đi có lại, ý định chia sẻ tri thức

\section{Keywords:}

Enjoyment, knowledge sharing intention, new product development, reciprocity, reward, tourism

\begin{abstract}
This study is to develop a theoretical model of the relationship between knowledge sharing intention (KSI) and new product development (NPD) in the tourism industry with the motivating role of personal motivation, includes enjoyment (ENJ), reciprocity (REC) and rewards (REW). The research hypotheses are verified by a structural equation modeling (SEM) based on survey data from 399 respondents who are employees of travel companies in Ho Chi Minh City. Findings revealed that all three factors of individual motivations such as ENJ, REC and REW have positive impacts on KSI. In addition, REW and KSI are found to enhance NPD in the tourism industry. Some managerial implications of the research findings are discussed.
\end{abstract}

\section{TÓM TẮT}

Mục tiêu của nghiên cứu này là phát triển mô hình lý thuyết về mối quan hệ giũa ý định chia sẻ tri thức (KSI) và phát triển sản phẩm mới (NPD) trong ngành du lịch với vai trò thúc đẩy của động lực cá nhân bao gồm niềm vui (ENJ), sư có đi có lại (REC) và phần thưởng (REW). Các giả thuyết nghiên cưu được kiểm chứng bằng mô hình cấu trúc tuyến tính (SEM) dựa vào dũ liệu thu thập tù 399 đáp viên là nhân viên của các công ty du lịch trên địa bàn thành phố Hồ Chí Minh. Kết quả nghiên cứu cho thấy ENJ, REC và REW đều có tác động tích cực đến KSI. Đồng thời, $R E W$ và KSI có vai trò thúc đẩy NPD trong ngành du lịch. Tù kết quả nghiên cưu, một số hàm ý quản trị với các nhà quản lý trong ngành du lịch được đề xuất.

\section{GIỚI THIỆU}

Trong những năm gần đây, du lịch đã trở thành một trong những ngành phát triển nhanh nhất của nền kinh tế thế giới và được công nhận rộng rãi về những đóng góp của nó đối với sự phát triển kinh tế khu vực và quốc gia (Liao et al., 2010). Thiết kế và phát triển sản phẩm du lịch đã trở thành những hoạt động quan trọng ở nhiều khu vực, quốc gia. Các nghiên cứu về phát triển sản phẩm mới trong ngành du lịch là rất cần thiết, nhằm cải thiện năng lực dự báo, hiểu rõ về hành vi du lịch, nâng cao sự hài lòng của du khách và tăng cường khả năng quản lý du lịch (Bramwell, 1998; Witt \& Witt , 1995). Sản phẩm du lịch tạo nên sự khác biệt trong phát triển du lịch, tạo nên thương hiệu và hình ảnh của mỗi điểm đến du lịch, của mỗi địa phương, mỗi vùng và mỗi quốc gia. Tuy nhiên, các sản phẩm du lịch Việt Nam còn trùng lặp giữa các vùng, chưa có tính đặc trưng và hấp dẫn riêng, chất lượng chưa cao (Lê Văn Minh, 2020). 
Trong giai đoạn hiện nay, ngành du lịch thế giới nói chung và Việt Nam nói riêng đang phải đối mặt với rất nhiều khó khăn, thách thức và chịu nhiều thiệt hại nặng nề do đại dịch COVID-19 gây ra. Vì vậy, để kích cầu du lịch và cũng để thỏa mãn nhu cầu trải nghiệm những sản phẩm mới, độc đáo của khách du lịch thì các công ty du lịch cần phải tạo ra các sản phẩm du lịch mới. Hơn nữa, các nghiên cứu gần đây (Chowdhury et al., 2020; Martínez-Pérez et al., 2016; Ogunmokun et al., 2020) đã khẳng định vai trò của quản trị và chia sẻ tri thức đối với việc phát triển các sản phẩm nhà hàng, khách sạn và du lịch. Tuy nhiên, các nghiên cứu này đều không xem xét các động lực cá nhân như là các tiền đề quyết định mối quan hệ giữa ý định chia sẻ tri thức và phát triển sản phẩm du lịch mới. Vì vậy, nghiên cứu này được thực hiện nhằm giải thích và điều tra thực nghiệm vai trò của các yếu tố động lực cá nhân đối với ý định chia sẻ tri thức, cũng như mức độ tác động của ý định chia sẻ tri thức đến phát triển sản phẩm mới trong các công ty du lịch tại thành phố (TP.) Hồ Chí Minh.

\section{CƠ SỞ LÝ THUYẾT VÀ PHÁT TRIỄN CÁC GIẢ THUYẾT}

\section{1. Động lực cá nhân và ý định chia sẻ tri thức}

Động lực đã được xác định là yếu tố quyết định đối với hành vi chung và hành vi liên quan đến công việc, nó là yếu tố thúc đẩy chuyển giao tri thức (Lin, 2007). Trong các nghiên cứu trước về động lực cá nhân, động lực được phân chia thành động lực bên ngoài và động lực bên trong (Kankanhalli et al., 2005). Động lực bên ngoài tập trung vào các lý do hướng đến mục tiêu, như phần thưởng hoặc lợi ích có được khi thực hiện một hành động, trong khi động lực bên trong chỉ ra niềm vui và sự hài lòng bản thân bắt nguồn từ một hành động cụ thể. Động lực bên ngoài và bên trong ảnh hưởng đến các ý định cá nhân liên quan đến một hành động cũng như các hành vi thực tế của họ (Lin, 2007). Động lực bên ngoài gồm có phần thưởng của tổ chức và sự có đi có lại (Kankanhalli et al., 2005). Phần thưởng của tổ chức thường được trao cho người cung cấp tri thức bởi hệ thống trả công của tổ chức như một loại kích thích bên ngoài dựa trên mối quan hệ trao đổi giữa người sử dụng lao động và người lao động (Hau et al., 2013). Sự có đi có lại là kết quả của quan hệ trao đồi có đi có lại giữa các nhân viên trong tổ chức. Sự có đi có lại khác với phần thưởng của tổ chức ở chỗ nó dựa trên mối quan hệ trao đổi giữa người cho và người nhận tri thức. Các nghiên cứu trước đã xác định sự có đi có lại là động lực bên ngoài có vai trò thúc đẩy chia sẻ tri thức (Kankanhalli et al., 2005; Wasko \& Faraj, 2005). Niềm vui khi tham gia chia sẻ tri thức tác động đến động lực bên trong của nhân viên. Niềm vui bắt nguồn từ người cho tri thức, là một loại động lực bên trong dựa trên mối quan hệ trao đổi giữa người cho tri thức và cái tôi của chính họ. Do đó, động lực bên trong thường chỉ ra động cơ thúc đẩy tâm lý như thích chia sẻ tri thức. Các nghiên cứu trước đây đã khẳng định rằng động lực bên trong có tác động tích cực đến việc chia sẻ tri thức (Hau et al., 2013).

\subsubsection{Niềm vui (Enjoyment)}

Niềm vui khi giúp đỡ người khác bắt nguồn từ khái niệm về lòng vị tha (Lin, 2007). Organ (1988) đã định nghĩa lòng vị tha bao gồm các hành vi tùy ý giúp đỡ những người khác với các nhiệm vụ hoặc vấn đề liên quan đến tổ chức. Nhân viên có thể được thúc đẩy bởi lòng vị tha tương đối do họ mong muốn giúp đỡ người khác (Davenport \& Prusak, 1998). Wasko and Faraj (2005) cho thấy rằng nhân viên về bản chất có động lực đóng góp tri thức vì tham gia vào các hoạt động trí tuệ và giải quyết vấn đề là thú vị và vì họ thích giúp đỡ người khác. Những người có được niềm vui khi giúp đỡ người khác bằng việc đóng góp tri thức có thể có định hướng thuận lợi hơn đối với việc chia sẻ tri thức và có xu hướng chia sẻ tri thức nhiều hơn (Lin, 2007). Ngoài ra, Cabrera et al. (2006) còn cho thấy khi nhân viên cảm nhận phần thưởng bên trong (niềm vui) về việc chia sẻ tri thức của mình càng nhiều thì họ càng có xu hướng tham gia chia sẻ tri thức nhiều hơn. Chennamaneni et al. (2012) nhận thấy rằng các cá nhân đóng góp vào tri thức của họ vì họ cảm thấy hài lòng khi giúp đỡ người khác.

Dựa vào các lập luận trên, giả thuyết $\mathrm{H} 1$ được đề xuất như sau:

H1: Niềm vui có tác động tích cực đến ý định chia sẻ tri thức.

\subsubsection{Sụ có đi có lại (Reciprocity)}

Hành vi có đi có lại đã được nhấn mạnh như một lợi ích của các cá nhân tham gia vào trao đổi xã hội (Blau, 1964). Hành vi có đi có lại có thể mang lại cảm giác mang ơn lẫn nhau, khiến những người đóng góp tri thức thường mong đợi sự giúp đỡ từ những người khác, hỗ trợ sự chia sẻ tri thức liên tục (Kollock, 1999). Hơn nữa, sự có đi có lại có thể tạo ra động lực hiệu quả để thúc đẩy chia sẻ tri thức và do đó đạt được sự hợp tác lâu dài lẫn nhau (Bock et al., 2005; Kankanhalli et al., 2005). Do đó, nếu nhân viên tin rằng họ có thể nhận được lợi ích có đi có lại từ các đồng nghiệp khác bằng cách chia sẻ tri thức 
của họ, thì có nhiều khả năng họ sẽ gặp thuận lợi trong việc chia sẻ tri thức hơn và do đó có ý định chia sẻ tri thức cao hơn (Lin, 2007). Trong tổ chức, những nhân viên sẵn sàng chia sẻ những ý tưởng chất lượng cao sẽ mong đợi những người khác phản hồi ý tưởng của họ và tạo ra những ý tưởng mới (Huang et al., 2011). Vì vậy, giả thuyết H2 được đề xuất như sau:

H2: Sự có đi có lại có tác động tích cực đến ý định chia sẻ tri thúc.

\subsubsection{Phần thương (Reward)}

Phần thưởng có thể là tiền tệ và phi tiền tệ. Phần thưởng bằng tiền có thể là tiền thưởng, sự khuyến khích. Phần thưởng phi tiền tệ có thể là giấy chứng nhận, sự công nhận của công chúng, sự đánh giá cao (Javaid et al., 2020). Phần thưởng của tổ chức rất hữu ích để thúc đẩy các cá nhân thực hiện các hành vi mong muốn (Lin, 2007). Phần thưởng của tổ chức có tác động tích cực trong việc khuyến khích nhân viên thực hiện các hành vi công việc khác nhau và nếu nhân viên có được nhiều phần thưởng hơn đối với việc chia sẻ tri thức thì họ sẽ sẵn sàng thực hiện chia sẻ tri thức nhiều hơn (Huang et al., 2011). Khi nhân viên nhận được phần thưởng kinh tế cho việc chia sẻ tri thức của họ, họ cảm thấy có động lực hơn để chia sẻ tri thức (Hau et al., 2013). Choi et al. (2008) cung cấp bằng chứng cho thấy cơ chế khen thưởng quan trọng hơn hỗ trợ kỹ thuật trong việc tạo động lực cho chia sẻ tri thức; phần thưởng bằng tiền có thể thúc đẩy ý định chia sẻ tri thức thông qua đóng góp của cá nhân vào cơ sở dữ liệu, tương tác chính thức trong và giữa các nhóm, và chia sẻ tri thức giữa các đơn vị làm việc. Tuy nhiên, chia sẻ tri thức thông qua các tương tác không chính thức phải được đền đáp bằng những động lực vô hình như sự công nhận (Bartol \& Srivastava, 2002).

Vì vậy, nghiên cứu được kỳ vọng rằng nếu nhân viên có niềm tin nhận được phần thưởng thì họ sẽ càng có ý định chia sẻ tri thức:

H3: Phần thuoơng của tổ chức có tác động tích cực đến ý định chia sẻ tri thúc.

\section{2. Ý định chia sẻ tri thức và phát triển sản phẩm mới}

Phát triển sản phẩm mới (NPD) là một trong các hoạt động đổi mới của doanh nghiệp tập trung vào quá trình đưa sản phẩm mới ra thị trường hoặc các sản phẩm mà khách hàng cảm nhận là mới (Hallak et al., 2018; Lee et al., 2016). Phát triển sản phẩm trong ngành dịch vụ thường được định nghĩa là các hoạt động kinh doanh liên quan đến việc phát triển các dịch vụ mới và cũng là cải tiến các dịch vụ hiện có, ngay cả khi chúng có vẻ là những thay đổi không đáng kể hoặc nhỏ (Cho et al., 2017). Nghiên cứu của Calantone et al. (1995) đã phân đoạn các hoạt động và hiệu quả kinh doanh liên quan đến việc phát triển sản phẩm thành cải tiến sản phẩm và phát triển sản phẩm mới. Cải tiến sản phẩm là các hoạt động nâng cao và sửa đổi các sản phẩm hiện có để đáp ứng nhu cầu của thị trường hiện tại và khách hàng của họ; còn phát triển mới là các hoạt động tạo ra sản phẩm mới để đáp ứng những nhu cầu của thị trường và khách hàng đối với các thị trường mới nổi và khách hàng mới của họ (He \& Wong, 2004). Rothaermel and Deeds (2004) cho rằng cải tiến sản phẩm đóng một vai trò tích cực trong ngắn hạn, trong khi phát triển mới là yếu tố cần thiết cho sự thành công dài hạn. Theo đó, phát triển sản phẩm đề cập đến các sản phẩm và dịch vụ mới hoặc được cải tiến đáng kể như giới thiệu vật liệu mới, sản phẩm trung gian, thành phần mới hoặc tính năng sản phẩm mới (Lee et al., 2016). Vì vậy, trong nghiên cứu này, phát triển sản phẩm mới được hiểu là các hoạt động đổi mới bao gồm cả hai quá trình cải tiến sản phẩm và phát triển mới các sản phẩm (Cho et al., 2017).

Phát triển sản phẩm mới đồng thời mang tính khám phá và khai thác (Benner \& Tushman, 2003; Tushman \& O'Reilly, 1996). Phát triển khám phá mới là những đổi mới triệt để và được thiết kế để đáp ứng nhu cầu của khách hàng hoặc thị trường mới nổi (Benner \& Tushman, 2003; Danneels, 2002). Các công ty sẽ đưa ra những thiết kế mới, tạo ra thị trường mới và phát triển các kênh phân phối mới (Abernathy \& Clark, 1985). Các phát triển khám phá mới đòi hỏi tri thức mới hoặc xuất phát từ tri thức hiện có (Benner \& Tushman, 2002; Levinthal \& March,1993; McGrath, 2001). Ngược lại, những phát triển mới mang tính khai thác là những đổi mới gia tăng và được thiết kế để đáp ứng nhu cầu của khách hàng hoặc thị trường hiện tại (Benner \& Tushman, 2003; Danneels, 2002). Các công ty mở rộng tri thức và kỹ năng hiện có, cải tiến các thiết kế, mở rộng các sản phẩm và dịch vụ hiện có, và tăng hiệu quả của các kênh phân phối hiện có (Abernathy \& Clark, 1985). Do đó, các phát triển khai thác mới được xây dựng dựa trên tri thức hiện có và củng cố các kỹ năng, quy trình và cấu trúc hiện tại (Abernathy \& Clark, 1985; Benner \& Tushman, 2002; Levinthal \& March, 1993).

Các hoạt động đổi mới có xu hướng dựa nhiều vào tri thức, kỹ năng và kinh nghiệm của nhân viên trong quá trình tạo ra giá trị (Wang \& Wang, 2012). Do đó, chia sẻ tri thức là yếu tố đóng góp quan trọng vào hiệu quả đổi mới và khả năng phát triển sản phẩm mới của công ty (Chang \& Lee, 2008; Wang 
\& Wang, 2012). Khi nhân viên bắt đầu chia sẻ tri thức, sẽ tạo cơ hội cho sự kết hợp những tri thức bổ sung mới, có thể thúc đẩy phát triển các sản phẩm mới để thỏa mãn nhu cầu thị trường (Tang \& Marinova, 2020). Ngoài ra, chia sẻ tri thức giúp nhân viên xử lý tốt hơn và sử dụng tri thức hiện có của họ để nâng cao hiệu quả đổi mới sản phẩm. Dựa vào các luận điểm trên, giả thuyết $\mathrm{H} 4$ được đề xuất như sau:

H4: Ý định chia sẻ tri thức có tác động tích cục đến phát triển sản phẩm móii.

\subsection{Phần thưởng và phát triển sản phẩm mới}

Hệ thống khen thưởng là yếu tố đóng góp quan trọng vào việc thực hiện chiến lược mang lại hiệu quả cũng như lợi thế cạnh tranh của một công ty (Wei \& Atuahene-Gima, 2009). Các nghiên cứu trước đây đã chỉ ra rằng hệ thống khen thưởng là công cụ giúp tăng hiệu quả của sản phẩm mới (Sarin \& Mahajan, 2001). Các phần thưởng có vai trò quan trọng đối với sự thành công của các sản phẩm mới. Việc giới thiệu các sản phẩm mới là rủi ro và tốn kém, vì vậy, sự khuyến khích và cam kết chấp nhận rủi ro là điều cần thiết cho sự thành công của sản phẩm mới của một công ty (Wei \& Atuahene-Gima, 2009).

Sarin and Mahajan (2001) đã đề xuất hai cách tiếp cận phần thưởng - phần thưởng dựa trên quá trình và phần thưởng dựa trên kết quả. Phần thưởng dựa trên quá trình là mức độ mà phần thưởng gắn liền với các quy trình, hành vi hoặc các phương tiện khác để đạt được kết quả mong muốn, ví dụ: hoàn thành các giai đoạn nhất định trong quá trình phát triển sản phẩm (Deschamps \& Nayak, 1995). Phần thưởng dựa trên kết quả là mức độ mà phần thưởng của tổ chức được gắn với kết quả cuối cùng. Quá trình phát triển sản phẩm mới có thể được chia thành hai giai đoạn chính: bắt đầu và thực hiện. Sự khác biệt giữa hai giai đoạn là giai đoạn bắt đầu nhấn mạnh đến việc hình thành ý tưởng về sản phẩm, trong khi giai đoạn thực hiện tập trung vào việc hoàn thiện ý tưởng đó (Nakata \& Sivakumar, 1996). Ở giai đoạn bắt đầu, việc chấp nhận rủi ro và chia sẻ tri thức chuyên sâu là cần thiết để tạo ra các ý tưởng về sản phẩm trước khi bước vào giai đoạn thực hiện, nơi phát sinh chi phí cao hơn. Do đó, mối quan tâm đáng kể đối với việc khen thưởng người lao động trong giai đoạn bắt đầu được đặt vào việc thúc đầy chia sẻ tri thức đa dạng và tối đa hóa số lượng và phạm vi tiếp cận phát triển sản phẩm, để có thể tạo ra những ý tưởng mạnh mẽ và khả thi. Phần thưởng dựa trên kết quả thúc đẩy sự hợp tác và gắn kết là những phương tiện hiệu quả ở giai đoạn thực hiện, nơi việc theo đuổi hiệu quả thị trường mong muốn trở thành mục tiêu của các doanh nghiệp (Nakata \& Sivakumar, 1996). Từ các lập luận trên, giả thuyết H5 được đề xuất như sau:

H5: Phần thưởng của tổ chức có tác động tích cực đến phát triển sản phẩm mới.

Mô hình lý thuyết cùng với các giả thuyết nghiên cứu đề xuất như Hình 1.

\section{Động lực cá nhân}

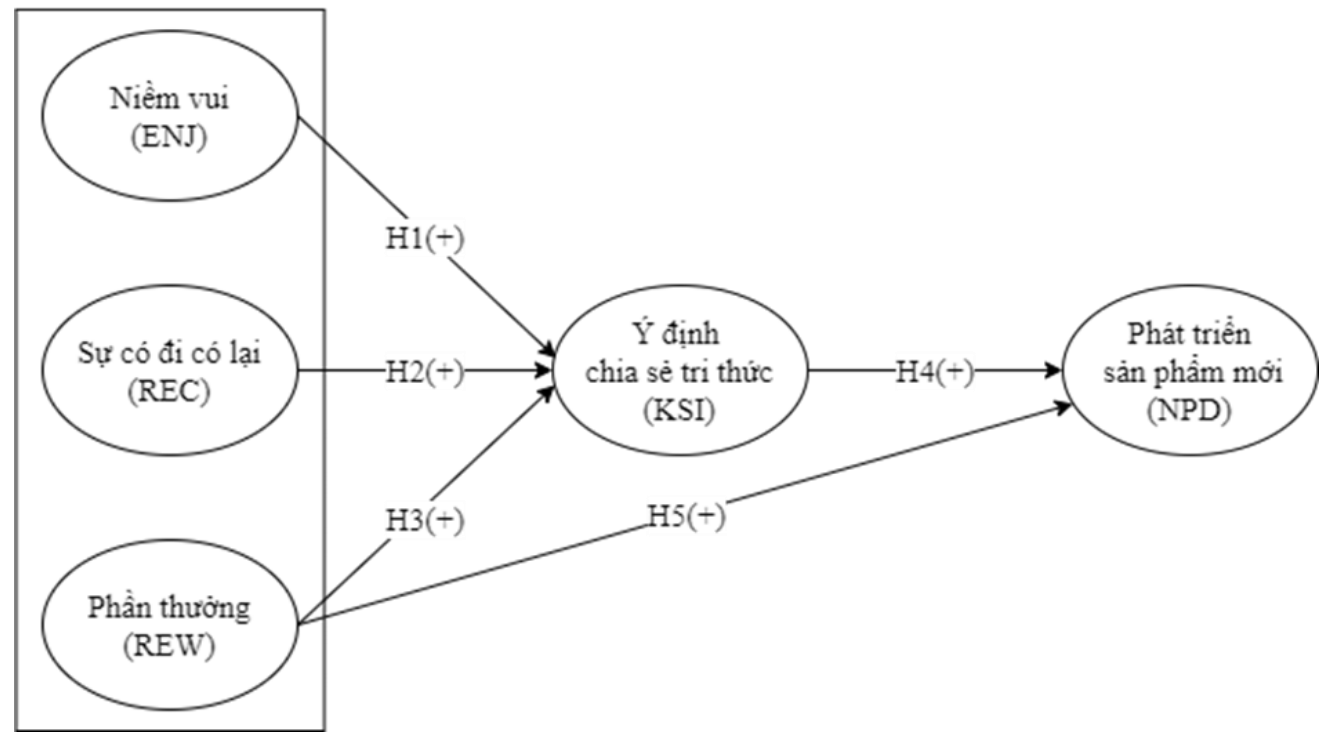

Hình 1. Mô hình nghiên cứu được đề xuất 


\section{PHƯƠNG PHÁP NGHIÊN CÚU}

\subsection{Chọn mẫu và thu thập dữ liệu}

Trong nghiên cứu về kinh doanh, nhà nghiên cứu có thể thu thập nhiều loại dữ liệu khác nhau từ những người trả lời là nhân viên, người tiêu dùng, người quản lý, nhà đầu tư và/hoặc nhà cung cấp bằng các phương pháp phổ biến như các cuộc phỏng vấn, quan sát và bản câu hỏi (Sekaran \& Bougie, 2016). Với lợi thế là ít tốn kém và tiết kiệm thời gian hơn so với phỏng vấn và quan sát, bản câu hỏi được thiết kế sẵn được sử dụng để làm công cụ khảo sát cho nghiên cứu này. Trong thời gian qua, ngành du lịch TP. Hồ Chí Minh luôn giữ vị trí, vai trò quan trọng trong phát triển kinh tế - xã hội của thành phố và cả nước. Đây là nơi có lực lượng lao động trực tiếp với trình độ đào tạo và kinh nghiệm trong ngành du lịch lớn nhất nước, hơn nữa còn là nơi tập trung nhiều cơ sở lưu trú, dịch vụ ăn uống, mua sắm, tổ chức hội nghị du lịch hàng đầu của Việt Nam (Nguyễn Tấn Trung, 2021). Vì vậy, tổng thể nghiên cứu là các công ty du lịch tại TP. Hồ Chí Minh và đáp viên là nhân viên đang làm việc tại các bộ phận kinh doanh, điều hành và phát triển thị trường của các đơn vị này. Cỡ mẫu càng lớn càng tốt và tối thiểu cho mô hình SEM sẽ bằng 5 lần số biến quan sát, nhưng không nhỏ hơn 200 (Hair et al., 2014; Kline, 2015). Để đạt được kích thước mẫu tối thiểu này, 450 bản câu hỏi (phát phiếu điều tra trực tiếp và thông qua hình thức trực tuyến trên Google Form) được gửi đến nhân viên của các công ty du lịch trên địa bàn TP. Hồ Chí Minh trong tháng 3 năm 2021. Sau khi sàng lọc để loại bỏ các mẫu điền không đầy đủ và dị biệt, 399 mẫu được thu đạt chuẩn để tiến hành phân tích dữ liệu.

\subsection{Thang đo}

Thang đo Likert 5 mức độ được sử dụng để đo lường các biến quan sát, trong đó "1" là "hoàn toàn không đồng ý" và " 5 " là "hoàn toàn đồng ý". Các thang đo được tham khảo từ các công trình nghiên cứu trước trong cùng lĩnh vực. Cụ thể:

\section{Bảng 1. Các cấu trúc và thang đo}

\section{Các cấu trúc và thang đo}

\section{Niềm vui $(\mathbf{E N J})$}

ENJ1 Tôi thích chia sẻ tri thức của mình với đồng nghiệp.

ENJ2 Tôi thích giúp đỡ đồng nghiệp bằng cách chia sẻ tri thức của mình.

ENJ3 Thật tốt khi giúp ai đó bằng cách chia sẻ tri thức của tôi.

ENJ4 Chia sẻ tri thức của tôi với đồng nghiệp là điều thú vị.

\section{Sự có đi có lại (REC)}

REC1 Khi tôi chia sẻ tri thức của mình với đồng nghiệp, tôi củng cố mối quan hệ giữa bản thân và họ.

REC2 Khi tôi chia sẻ tri thức của mình với đồng nghiệp, tôi mở rộng phạm vi liên kết của mình với họ.

REC3 Khi tôi chia sẻ tri thức của mình với đồng nghiệp, tôi mong đợi nhận lại tri thức khi cần thiết.

REC4 Khi tôi chia sẻ tri thức của mình với đồng nghiệp, tôi tin rằng những yêu cầu về tri thức trong tương lai của tôi sẽ được đáp lại.

\section{Phần thưởng của tổ chức (REW)}

REW1 Tôi sẽ nhận được một mức lương cao hơn để đổi lại sự chia sẻ tri thức của tôi.

REW2 Tôi sẽ nhận được phần thưởng cao hơn để đổi lại việc chia sẻ tri thức của mình.

REW3 Tôi sẽ nhận được nhiều cơ hội thăng tiến hơn để đồi lại những chia sẻ tri thức của tôi.

REW4 Tôi sẽ nhận được sự an toàn trong công việc để đổi lại sự chia sẻ tri thức.

\section{4. Ý định chia sẻ tri thức (KSI)}

KSI1 Tôi sẽ chia sẻ cách làm việc của mình với đồng nghiệp thường xuyên hơn trong tương lai.

KSI2 Tôi sẽ luôn cung cấp phương pháp làm việc và tri thức của mình cho đồng nghiệp.

KSI3 Tôi dự định sẽ chia sẻ kinh nghiệm hoặc bí quyết làm việc của mình với đồng nghiệp thường xuyên hơn trong tương lai.

KSI4 Tôi sẽ luôn cung cấp bí quyết của mình theo yêu cầu của đồng nghiệp.

KSI5 Tôi sẽ cố gắng chia sẻ tri thức chuyên môn từ quá trình đào tạo của mình với đồng nghiệp theo cách hiệu quả hơn.

\section{Phát triển sản phẩm mới (NPD)}

NPD1 Công ty tôi thường xuyên thực hiện các thay đổi đối với các sản phẩm hiện có.

NPD2 Công ty tôi thường xuyên cải tiến các sản phẩm hiện có dựa trên nhu cầu của khách hàng hiện tại.

NPD3 Công ty tôi thường xuyên phát triển các sản phẩm mới.

NPD4 Công ty tôi thường xuyên áp dụng các kỹ năng mới để phát triển các sản phẩm mới.

NPD5 Công ty tôi thường xuyên khám phá khách hàng và thị trường mới. 
Niềm vui (ENJ) gồm 4 biến (ENJ1 đến ENJ4) tham khảo từ Lin (2007), thang đo này tập trung vào nhận thức của nhân viên về niềm vui có được thông qua việc chia sẻ tri thức. Sự có đi có lại (REC) gồm 4 biến (REC1 đến REC4) dựa theo Kankanhalli et al. (2005), đề cập đến niềm tin của nhân viên rằng việc chia sẻ tri thức hiện tại sẽ dẫn đến việc đáp ứng các yêu cầu tri thức trong tương lai. Phần thưởng của tổ chức (REW) được đo bằng 4 biến (REW1 đến REW4), tham khảo từ Lin (2007) nhằm đo lường mức độ mà nhân viên tin rằng họ sẽ nhận được các khuyến khích bên ngoài (chẳng hạn như khuyến khích tiền lương, tiền thưởng, khuyến khích thăng chức, hoặc đảm bảo công việc) thông qua chia sẻ tri thức. Ý định chia sẻ tri thức (KSI) gồm 5 biến (KSI1 đến KSI5) được phát triển từ Chow and Chan (2008) và Hau et al. (2013), nhằm đánh giá khả năng nhân viên chia sẻ tri thức. Cuối cùng, 5 biến (NPD1 đến NPD5) được sử dụng phát triển từ Cho et al. (2017) và Jansen et al. (2006) để đo lường phát triển sản phẩm mới (NPD). Các biến quan sát của NPD được đo lường bằng cách đánh giá các hoạt động của công ty liên quan đến việc nâng cao sản phẩm và phát triển sản phẩm mới. Trong đó, nâng cao sản phẩm được đo lường bằng các hoạt động liên quan đến việc thay đổi, cải tiến các sản phẩm hiện có để đáp ứng nhu cầu hiện tại của khách hàng, còn phát triển mới sản phẩm cũng được đo lường bằng các hoạt động của công ty liên quan đến việc phát triển các sản phẩm mới để đáp ứng nhu cầu của khách hàng và thị trường mới đang phát triển. Các thang đo được trình bày trong Bảng 1 .

\subsection{Phân tích dữ liệu}

Phân tích dữ liệu được thực hiện theo phương pháp tiếp cận hai bước do Anderson and Gerbing (1988) khuyến nghị. Đầu tiên, một mô hình đo lường được thiết lập thông qua phân tích nhân tố khẳng định $(\mathrm{CFA})$ và sau đó, sử dụng phần mềm AMOS 24 để phân tích đường dẫn và ước tính hệ số đường dẫn. Để đánh giá tính hợp lệ của mô hình đo lường, hai phép đánh giá là giá trị hội tụ (convergent validity) và giá trị phân biệt (discriminant validity) được thực hiện. Nghiên cứu đã kiểm tra tính giá trị hội tụ bằng cách đánh giá tải nhân tố chuẩn hóa phải có ý nghĩa đối với tất cả các biến tiềm ẩn (Anderson \& Gerbing, 1988); độ tin cậy tổng hợp (CR) phải trên 0,70 và phương sai trung bình được trích xuất (AVE) phải lớn hơn 0,50 cho tất cả các cấu trúc (Fornell \& Larcker, 1981; Hair et al., 2014). Để đánh giá tính giá trị phân biệt, phương pháp tiếp cận của Fornell and Larcker (1981) được sử dụng, trong đó AVE cho mỗi cấu trúc phải lớn hơn mối tương quan bình phương giữa một cấu trúc với bất kỳ cấu trúc khác (MSV).

Sự phù hợp của mô hình đo lường và mô hình cấu trúc được đánh giá theo đề xuất của Hair et al. (2014), đó là nếu kiểm định Chi bình phương có pvalue $<0,05$ thì mô hình phù hợp với các nghiên cứu trước đây. Nếu chỉ số CMIN/df nhỏ hơn 3 thì mô hình phù hợp tốt, CMIN/df nhỏ hơn 5 thì đôi khi vẫn có thể chấp nhận. Số dư bình phương gốc chuẩn hóa (SRMR) càng nhỏ càng tốt (SRMR $<0,08)$. Các chỉ số phù hợp so sánh (CFI), chỉ số Tucker-Lewis (TLI) trên 0,92 và sai số ước lượng căn quân phương (RMSEA) nhỏ hơn 0,07. Ngoài ra, theo Hu and Bentler (1999) thì chỉ số CFI trên 0,90 và RMSEA nhỏ hơn 0,08 cũng có thể chấp nhận được.

\section{KẾT QUẢ VÀ THẢO LUẬN}

\subsection{Kết quả nghiên cứu}

\subsection{1. Đặc điểm mẫu nghiên cúu}

Bảng 2. Bảng mô tả mẫu nghiên cứu theo đặc điểm nhân khẩu học

\begin{tabular}{lrr}
\hline Đặc điểm & $\begin{array}{r}\text { Số } \\
\text { lượng }\end{array}$ & $\begin{array}{r}\text { Tỉ lệ phần } \\
\text { trăm (\%) }\end{array}$ \\
\hline Giới tính: & & \\
- Nữ & 195 & 48,9 \\
- Nam & 204 & 51,1 \\
\hline Tuổi: & & \\
- 21 - 25 & 23 & 5,8 \\
- 26 - 30 & 145 & 36,3 \\
- 31 - 35 & 172 & 43,1 \\
- 36 - 40 & 52 & 13,0 \\
- Trên 40 & 7 & 1,8 \\
\hline Trình độ học vấn: & & \\
- Trung cấp & 4 & 1,0 \\
- Cao đẳng & 21 & 5,2 \\
- Đại học & 268 & 67,2 \\
- Thạc sĩ & 17 & 4,3 \\
- Khác & 89 & 22,3 \\
\hline Kinh nghiệm công tác (năm): & & \\
- Dưới 3 & 31 & 7,7 \\
- 3 - 5 & 102 & 25,6 \\
- 6 - 10 & 134 & 33,6 \\
- 11 - 15 & 79 & 19,8 \\
- Trên 15 & 53 & 13,3 \\
\hline \multicolumn{2}{c}{ Số mẫu N $=399$} \\
\hline
\end{tabular}

Bảng 2 mô tả đặc điểm nhân khẩu học của 399 đáp viên, bao gồm giới tính, độ tuổi, trình độ học vấn và kinh nghiệm công tác. Kết quả thống kê cho thấy tỷ lệ nam và nữ trong mẫu khảo sát khá tương đồng, với tỷ lệ tương ứng $51,1 \%$ nam và $48,9 \%$ nữ. Về độ tuổi, phần lớn nhân viên của các công ty du 
lịch được khảo sát trong độ tuổi 31 - 35 tuổi, chiếm tỉ lệ 43,1\%, có 5,8 \% nhân viên độ tuổi 21 - 25 tuổi, độ tuổi từ 26 - 30 chiếm $36,3 \%$, độ tuổi từ 36 - 40 chiếm 13,0\% và độ tuổi lớn hơn 40 tuổi chiếm 1,8 $\%$. Về trình độ học vấn, trung cấp chiếm rất ít $1,0 \%$, cao đẳng chiếm $5,2 \%$, phần lớn là đại học chiếm $67,2 \%$, còn lại là thạc sĩ chiếm $4,3 \%$ và trình độ khác là $22,3 \%$. Bên cạnh đó, nhân viên trong các công ty du lịch này có số năm kinh nghiệm làm việc dưới 3 năm là $7,7 \%$, từ $3-5$ năm chiếm $25,6 \%$, từ 5 - 10 năm chiếm $33,6 \%$, từ 10 - 15 năm chiếm 19,8 $\%$ và còn lại $13,3 \%$ nhân viên có thời gian làm việc trên 15 năm. Số liệu cụ thể được trình bày ở Bảng 2 .

\subsubsection{Mô hình đo lường}

Kết quả phân tích hệ số tải nhân tố chuẩn hóa của tất cả các biến tiềm ẩn cũng như các giá trị Cronbach's Alpha của tất cả các cấu trúc trong mô hình đo lường của nghiên cứu này được trình bày trong Bảng 3.

Trong mô hình của nghiên cứu, tất cả các tải nhân tố chuẩn hóa đều có ý nghĩa ở mức 0,001 . Tất cả độ tin cậy CR (từ 0,831 : REC đến $0,906: \mathrm{KSI}$ ) đều nằm trên mức được chấp nhận là 0,70 (Fornell \& Larcker, 1981; Hair et al., 2014) và tất cả các giá trị AVE (từ 0,553: Sự có đi có lại - REC đến 0,660: Ý định chia sẻ tri thức - KSI) đều nằm trên giá trị được chấp nhận là 0,50 (Fornell \& Larcker, 1981; Hair et al., 2014). Điều này chỉ ra rằng mô hình của nghiên cứu đáp ứng các tiêu chí về tính giá trị hội tụ. Độ tin cậy Cronbach's alpha của năm cấu trúc nằm trong khoảng từ 0,828 (REC) đến $0,906(\mathrm{KSI})$ cho thấy rằng các thang đo nội bộ phù hợp với tiêu chuẩn khuyến nghị là 0,70 (Kline, 2015). Ngoài ra, căn bậc hai AVE của mỗi cấu trúc lớn hơn mối tương quan giữa nó và bất kỳ cấu trúc nào khác (Fornell \& Lacker, 1981) và không có tương quan bình phương (MSV) nào vượt qua $\mathrm{AVE}$, điều này chứng tỏ mô hình đo lường đạt được tính giá trị phân biệt (Bảng 4). Như vậy, tính giá trị hội tụ và tính giá trị phân biệt của mô hình nghiên cứu đã được kiểm định và đều được chấp nhận.

Bảng 3. Hệ số tải nhân tố chuẩn hóa và giá trị Cronbach's Alpha của các cấu trúc

\begin{tabular}{ccr}
\hline $\begin{array}{l}\text { Các cấu trúc và biến } \\
\text { quan sát }\end{array}$ & Hệ số tải & $\begin{array}{r}\text { Cronbach's } \\
\text { alpha }\end{array}$ \\
\hline 1. Niềm vui (ENJ) & & 0,859 \\
\hline ENJ1 & 0,772 & \\
ENJ2 & 0,683 & \\
ENJ3 & 0,829 & \\
ENJ4 & 0,823 & \\
\hline 2. Sự có đi có lại (REC) & & 0,828 \\
\hline REC1 & 0,639 & \\
REC2 & 0,797 & \\
REC3 & 0,838 & \\
REC4 & 0,680 & \\
\hline 3. Phần thưởng của tổ chức (REW) & 0,859 \\
\hline REW1 & 0,707 & \\
REW2 & 0,801 & \\
REW3 & 0,821 & \\
REW4 & 0,789 & \\
\hline 4. Ý định chia sẻ tri thức (KSI) & 0,906 \\
\hline KSI1 & 0,717 & \\
KSI2 & 0,778 & \\
KSI3 & 0,798 & \\
KSI4 & 0,844 & \\
KSI5 & 0,857
\end{tabular}

\begin{tabular}{ccc}
\hline 5. Phát triển sản phẩm mới (NPD) & 0,865 \\
\hline NPD1 & 0,797 & \\
NPD2 & 0,724 & \\
NPD3 & 0,771 & \\
NPD4 & 0,749 & \\
NPD5 & 0,690 & \\
\hline
\end{tabular}

Bảng 4. Độ tin cậy và tính giá trị của mô hình CFA

\begin{tabular}{lrrrrrrrrr}
\hline & CR & AVE & MSV & $\begin{array}{c}\text { Căn bậc 2 } \\
\text { của AVE }\end{array}$ & NPD & KSI & ENJ & REC & REW \\
\hline NPD & 0,867 & 0,567 & 0,519 & 0,753 & 1 & & & & \\
KSI & 0,906 & 0,660 & 0,519 & $0,8130,721^{* * *}$ & 1 & & & \\
ENJ & 0,860 & 0,607 & 0,366 & $0,7790,407^{* * *}$ & $0,511^{* * *}$ & 1 & & \\
REC & 0,831 & 0,553 & 0,366 & $0,7440,394^{* * *}$ & $0,494^{* * *}$ & $0,605^{* * *}$ & 1 & \\
REW & 0,861 & 0,609 & 0,496 & $0,7800,704 * * *$ & $0,701 * * *$ & $0,425^{* * * *}$ & $0,475^{* * *}$ & 1 \\
\hline
\end{tabular}

Kết quả phân tích sự phù hợp của mô hình đo lường (Model fit) bằng phần mềm AMOS 24 cho thấy rằng các chỉ số: $\chi^{2}=479,898(\mathrm{df}=199)$; $\mathrm{CMIN} / \mathrm{df}=2,412<3, \mathrm{P}$-value $=0,000 \leq 0,05$. Các chỉ số $\mathrm{CFI}=0,945, \mathrm{TLI}=0,936$ đều có giá trị trên mức giá trị ngưỡng là 0,92 (Hair et al., 2014). Cùng với đó là hệ số $\mathrm{RMSEA}=0,060$ và $\mathrm{SRMR}=0,0392$ đều thấp hơn các giá trị cắt theo đề xuất của Hair et al. (2014). Do đó, có thể kết luận rằng các cấu trúc trong mô hình giả thuyết là hợp lệ, đáng tin cậy và khác biệt với nhau (Fornell \& Lacker, 1981; Hair et al., 2014). 


\subsubsection{Mô hình cấu trúc}

Ở bước phân tích này, mô hình sẽ được kiểm tra các chỉ số phù hợp tổng thể của nó và kiểm định các giả thuyết nghiên cứu đã được đề xuất.

Kết quả phân tích sự phù hợp của mô hình cấu trúc cho thấy rằng chỉ số $\chi^{2}=634,964(\mathrm{df}=203)$; $\mathrm{CMIN} / \mathrm{df}=3,128$, giá trị này thấp hơn mức ngưỡng (bằng 5) và $\mathrm{P}$-value $=0,000 \leq 0,05$. Các chỉ số $\mathrm{CFI}$ $=0,915, T L I=0,903$ và $R M S E A=0,073$ đều đạt giá trị tối thiểu (Hu \& Bentler, 1999). Những kết quả này cho thấy rằng mô hình cấu trúc là hoàn toàn phù hợp theo đề xuất của $\mathrm{Hu}$ and Bentler (1999).

Kết quả phân tích dữ liệu nghiên cứu đối với mô hình cấu trúc đề xuất (Bảng 5) cho ta thấy rằng biến tiềm ẩn niềm vui (ENJ) có trọng số $\beta=0,211$ với $\mathrm{p}$ $<0,001$; sự có đi có lại (REC) có $\beta=0,147$ với $p<$ 0,001 và phần thưởng (REW) có trọng số $\beta=0,584$ với $\mathrm{p}<0,001$, điều này chứng tỏ $E N J, R E C$ và $R E W$ đều có tác động trực tiếp và có ý nghĩa thống kê đến ý định chia sẻ tri thức (KSI), nghĩa là tất cả các giả thuyết $\mathrm{H} 1, \mathrm{H} 2, \mathrm{H} 3$ đều được chấp nhận với mức ý nghĩa thống kê $\mathrm{p}<0,001$. Sau đó, ý định chia sẻ tri thức (có $\beta=0,396 ; p<0,001)$ cũng có ảnh hưởng tích cực đến phát triển sản phẩm mới (NPD), do đó chấp nhận giả thuyết $\mathrm{H} 4$ với $\mathrm{p}<0,001$. Cuối cùng, giả thuyết $\mathrm{H} 5$ cho rằng phần thưởng của tổ chức (REW) có ảnh hưởng tích cực, trực tiếp đến phát triển sản phẩm mới (NPD) của công ty cũng được hỗ trợ (với $\beta=0,439 ; p<0,001)$.

\section{Bảng 5. Kết quả kiểm định giả thuyết nghiên cứu}

\begin{tabular}{|c|c|c|c|c|c|}
\hline$\overline{\text { Giả }}$ & yết & Kỳ vọng & Trọng số chuẩn hóa & p-value & Kết quả \\
\hline$\overline{\mathrm{H} 1}$ & $\mathrm{ENJ} \rightarrow \mathrm{KSI}$ & + & 0,211 & $0,000(\mathrm{p}<0,001)$ & Chấp nhận \\
\hline $\mathrm{H} 2$ & $\mathrm{REC} \rightarrow \mathrm{KSI}$ & + & 0,147 & $0,001(p=0,001)$ & Chấp nhận \\
\hline H3 & $\mathrm{REW} \rightarrow \mathrm{KSI}$ & + & 0,584 & $0,000(\mathrm{p}<0,001)$ & Chấp nhận \\
\hline $\mathrm{H} 4$ & $\mathrm{KSI} \rightarrow \mathrm{NPD}$ & + & 0,439 & $0,000(\mathrm{p}<0,001)$ & Chấp nhận \\
\hline H5 & $\mathrm{REW} \rightarrow \mathrm{NPD}$ & + & 0,396 & $0,000(\mathrm{p}<0,001)$ & Chấp nhận \\
\hline
\end{tabular}

Trong mô hình SEM, chỉ số thống kê tương quan bình phương $(\mathrm{SMC})$ của mô hình là chỉ số tỉ lệ biến thiên của biến nội sinh được các biến ngoại sinh giải thích. Chỉ số SMC càng lớn thì khả năng giải thích của mô hình càng lớn. Các hệ số $\mathrm{SMC}$ nằm trong khoảng từ 0 đến 1 (Byrne, 2016). Trong mô hình cấu trúc hiện tại, hệ số SMC của phát triển sản phẩm mới (NPD) là $0,583(58,3 \%)$, điều này cho thấy $58,3 \%$ biến thiên của NPD được giải thích bởi biến thiên trong ý định chia sẻ tri thức (KSI) và phần thưởng của tô chức (REW). Trong khi đó, ý định chia sẻ tri thức (KSI) có hệ số SMC là $0,512(51,2 \%)$, điều này có nghĩa là $51,2 \%$ biến thiên của KSI được giải thích bởi biến thiên trong niềm vui (ENJ), sự có đi có lại $(\mathrm{REC})$ và phần thưởng $(\mathrm{REW})$.

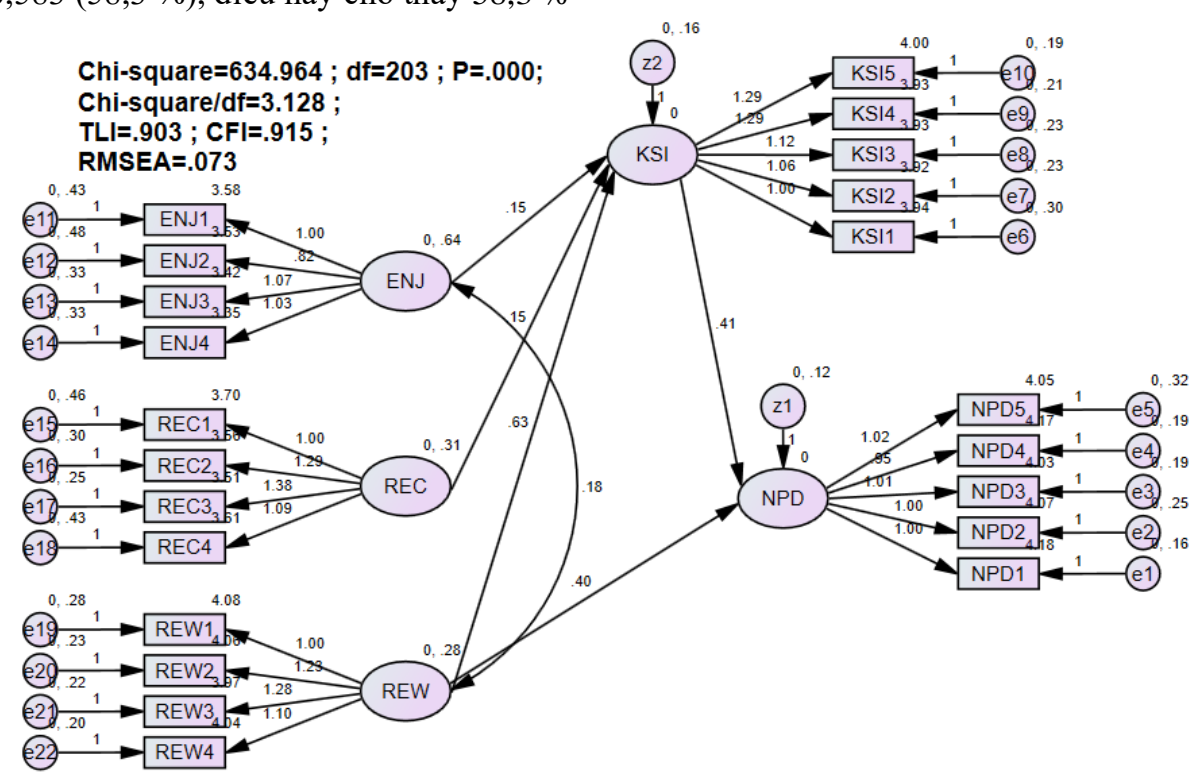

Hình 2. Mô hình cấu trúc

Kết quả phân tích đường dẫn đối với các giả thuyết đề xuất trong nghiên cứu được mô tả như Hình 3. 


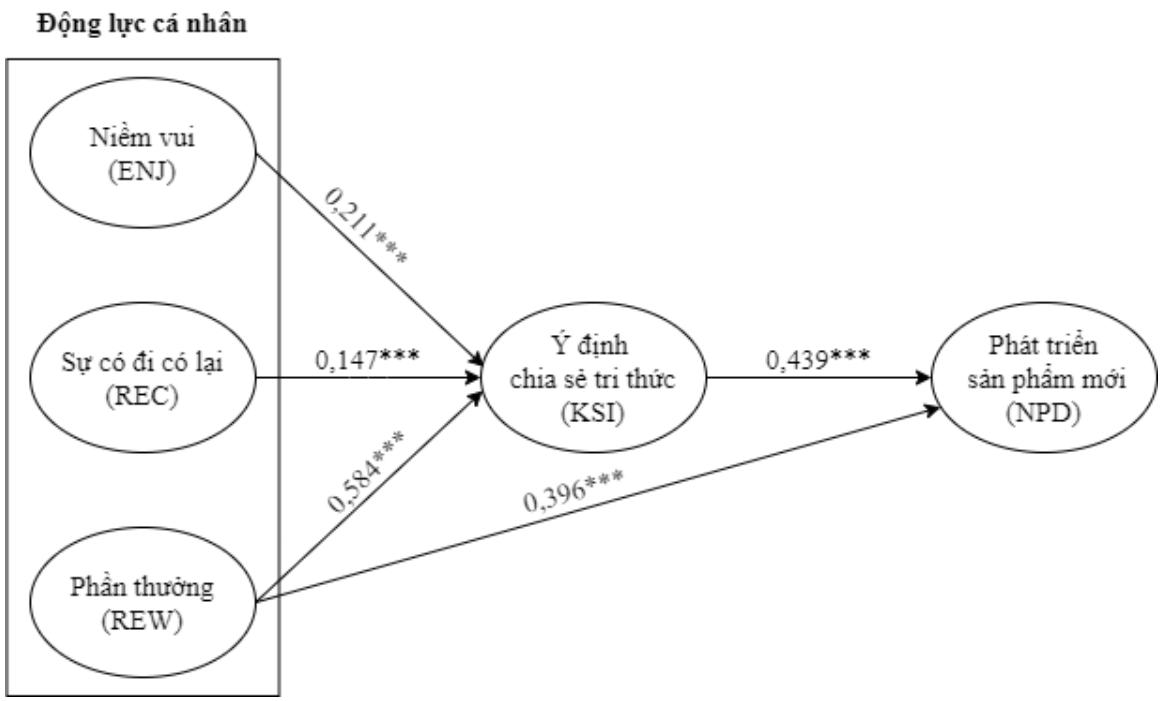

Hình 3. Kết quả nghiên cứu

Ghi chú: ***: $p<0,001$

\subsection{Thảo luận kết quả}

Nhân tố thúc đẩy ý định chia sẻ tri thức của các nhân viên trong các công ty du lịch và việc chia sẻ tri thức sẽ mang lại lợi ích như thế nào đối với những nhân viên có ý định chia sẻ được thảo luận. Các nhân tố của động lực cá nhân bao gồm niềm vui, sự có đi có lại và phần thưởng như là tiền đề của ý định chia sẻ tri thức và phát triển sản phẩm mới trong ngành du lịch được xem xét. Kết quả của phân tích mô hình cấu trúc đã chứng minh tất cả các mối tương quan đều được chấp nhận.

Kết quả nghiên cứu cho thấy tất cả 3 nhân tố động lực cá nhân là niềm vui, sự có đi có lại và phần thưởng của tổ chức đều có tác động tích cực, trực tiếp đến ý định chia sẻ tri thức với các mức độ tác động khác nhau. Trong đó, phần thưởng có tác động mạnh nhất với trọng số hồi quy chuẩn hóa bằng 0,584 , kế tiếp là niềm vui với trọng số bằng 0,211 và sau cùng, tác động thấp nhất trong ba nhân tố động lực cá nhân là sự có đi có lại với hệ số chuẩn hóa bằng 0,147 . Các kết quả này củng cố cho lý thuyết hiện tại về mối quan hệ giữa động lực cá nhân và ý định chia sẻ tri thức.

Các tổ chức có thể thúc đẩy văn hóa chia sẻ tri thức không chỉ bằng cách trực tiếp đưa tri thức vào chiến lược kinh doanh của họ mà còn bằng cách thay đổi thái độ và hành vi của nhân viên để thúc đẩy sự sẵn sàng chia sẻ tri thức (Lin, 2007). Theo lý thuyết kỳ vọng (Vroom, 1964), càng có nhiều kết quả tích cực được coi là gắn liền với một hành động nhất định, thì mọi người càng có xu hướng thực hiện hành động đó. Từ góc độ nghiên cứu hành vi công việc, động lực bên ngoài (phần thưởng) đã được chứng minh là có ảnh hưởng đáng kể đến sự tham gia của người lao động (Fenwick \& Olson, 1986). Do đó, một số hình thức động lực bên ngoài, ví dụ khuyến khích tiền tệ hoặc khen ngợi và công nhận, có thể thúc đẩy chia sẻ tri thức. Ngoài ra, các nghiên cứu trước đây cũng chỉ ra rằng sự gia tăng động lực bên trong có liên quan đến việc nhân viên sằn sàng tạo ra tâm trạng tích cực, dẫn đến tăng cường học tập và có xu hướng tham gia chia sẻ tri thức tự nguyện (Osterloh \& Frey, 2000). Lin (2007) đã giải thích và chứng minh vai trò của cả động lực bên ngoài (phần thưởng tổ chức và sự có đi có lại) và động lực bên trong (niềm vui khi giúp đỡ người khác) đối với ý định chia sẻ tri thức của nhân viên.

Niềm vui trong việc giúp đỡ người khác có tác động tích cực đến ý thức chia sẻ tri thức. Kết quả này hoàn toàn giống với nghiên cứu của Lin (2007) và Hau et al. (2013) về vai trò của niềm vui trong thúc đẩy hành vi chia sẻ tri thức. Sự có đi có lại có ảnh hưởng đến ý định chia sẻ tri thức của nhân viên. Kết quả này phù hợp với Scott (2000) cho rằng khả năng hợp tác phụ thuộc rất nhiều vào niềm tin về sự có đi có lại và việc chia sẻ tri thức sẽ không xảy ra tự nguyện nếu không có sự có đi có lại đó. Tamjidyamcholo et al. (2013) phát hiện ra rằng sự có đi có lại có tác động tích cực đến ý định và thái độ chia sẻ tri thức. Phần thưởng của tổ chức có ảnh hưởng tích cực đến ý định chia sẻ tri thức. Điều này chứng minh rằng sự mong đợi của cá nhân về phần thưởng có vai trò thúc đẩy chia sẻ tri thức. Nghiên cứu của Javaid et al. (2020) chỉ ra rằng phần thưởng 
có vai trò quan trọng trong thúc đẩy ý định chia sẻ tri thức.

Nghiên cứu này cũng cung cấp bằng chứng cho thấy ý định chia sẻ tri thức có tác động tích cực đến phát triển sản phẩm du lịch mới (giả thuyết $\mathrm{H} 4$ ). Kết quả này phù hợp với nghiên cứu của Chowdhury et al. (2020) về vai trò thúc đẩy của ý định chia sẻ tri thức đối với phát triển sản phẩm mới trong ngành nhà hàng. Kết quả này khẳng định rằng sự sẵn sàng chia sẻ thông tin và tri thức giữa các thành viên trong tổ chức sẽ tạo điều kiện thuận lợi cho việc phát triển các sản phẩm mới. Ogunmokun et al. (2020) cũng chỉ ra rằng chia sẻ tri thức sẽ thúc đẩy cho việc đổi mới sản phẩm, dịch vụ. Điều này có nghĩa là nhân viên sẽ cam kết đưa ra những cách thức sáng tạo để cung cấp dịch vụ mới, hiệu quả trong tổ chức của họ nếu họ được khuyến khích chia sẻ tri thức trong tổ chức (Chang \& Lee, 2008; Chowdhury et al., 2020; Wang \& Wang, 2012).

Kết quả kiểm định của giả thuyết $\mathrm{H} 5$ phát hiện ra rằng phần thưởng có ảnh hưởng trực tiếp đến phát triển sản phẩm du lịch mới. Kết quả này phù hợp với Chang et al. (2007) chứng minh hệ thống phần thưởng có tác động đến hiệu quả của phát triển sản phẩm mới, cũng như Wei and Atuahene-Gima (2009) kết luận rằng các phần thưởng dài hạn có vai trò thúc đẩy phát triển sản phẩm mới của tổ chức. Các phần thưởng của tổ chức có thể ảnh hưởng đến thái độ và hành vi của nhân viên, sự nhận thức công bằng trong phần thưởng có thể thay đổi thái độ và hành vi của nhân viên đối với việc đóng góp nồ lực của họ cho tổ chức (Chang et al., 2007). Một vấn đề quan trọng mà các nhà quản lý đổi mới phải đối mặt là làm thế nào để thực hiện quyền kiểm soát đầy đủ của người quản lý đối với các nhóm phát triển sản phẩm mới để đảm bảo đáp ứng các mục tiêu của tổ chức. Các công ty nên kết hợp việc kiểm soát quá trình và sử dụng các phần thưởng dựa trên quá trình khi mục tiêu của họ là phát triển các sản phẩm mới với chất lượng cao (Carbonell \& RodríguezEscudero, 2015).

\section{3. Đề xuất}

Dựa vào kết quả nghiên cứu, một số đề xuất để tăng cường ý định chia sẻ tri thức của nhân viên nhằm phát triển sản phẩm mới trong ngành du lịch như sau:

Niềm vui trong việc giúp đỡ người khác ảnh hưởng đáng kể đến thái độ và ý định chia sẻ tri thức của nhân viên, do đó các nhà quản lý cần tăng mức độ thích thú mà nhân viên có được khi họ giúp đỡ nhau thông qua chia sẻ tri thức bằng việc liên kết các sáng kiến chia sẻ tri thức với các sứ mệnh trách nhiệm xã hội của công ty và các hoạt động cộng đồng. Các nhà quản lý cần quan tâm đến việc phát triển và duy trì chia sẻ tri thức trong toàn bộ tổ chức mình bằng cách tập trung vào việc nâng cao trạng thái tâm trạng tích cực của nhân viên, tạo không khí thoải mái, cởi mở trong môi trường làm việc để họ cảm thấy vui vẻ, thú vị khi chia sẻ tri thức với các đồng nghiệp, và luôn sẵn sàng giúp đỡ đồng nghiệp khi có khó khăn trong thực hiện nhiệm vụ.

Các nhà quản lý có thể tăng cường tính có đi có lại trong đội ngũ nhân viên của họ bằng cách nhấn mạnh và thúc đẩy bản chất có đi có lại của việc trao đổi tri thức trong tổ chức của mình, chẳng hạn như xây dựng và thực hiện quy tắc hỏi đáp trong hệ thống quản lý tri thức ở cấp độ cá nhân và các sáng kiến tạo tri thức hợp tác giữa các đơn vị như các kế hoạch đổi mới quy trình xuyên chức năng giữa các nhóm, tổ, đơn vị. Các mối quan hệ gần gũi, có đi có lại có tác động đến cả chia sẻ tri thức hiện và tri thức ẩn. Người đứng đầu trong các công ty, tổ chức sẽ chịu trách nhiệm về việc ra các quyết định cuối cùng mà các quyết định này được tham mưu bởi các đơn vị của công ty. Do đó, nếu nhân viên của các đơn vị đó có mối quan hệ một cách chặt chẽ, gần gũi với nhau cũng như với các chuyên gia liên quan thì quá trình trao đổi thông tin sẽ được thúc đẩy để từ đó hoạch định các chính sách có hiệu quả cho công ty mình.

Để khuyến khích nhân viên chia sẻ tri thức, các công ty du lịch có thể xây dựng hệ thống khen thưởng phi tiền tệ và hệ thống khen thưởng tiền tệ. Phần thưởng tiền tệ có thể là tăng lương và tiền thưởng cho những nhân viên có thành tích xuất sắc trong việc chia sẻ và chuyển giao tri thức trong tổ chức. Phần thưởng phi tiền tệ thể hiện bằng sự công nhận, biểu dương các nhân viên có vai trò tích cực đối với việc thúc đẩy chia sẻ tri thức, chẳng hạn như tạo cơ hội ưu tiên trong đào tạo, phát triển. Các nhà quản lý, lãnh đạo cần khuyến khích nhân viên tích cực học tập nâng cao trình độ và chia sẻ những kiến thức tiếp thu với các nhân viên khác. Các loại hình đào tạo được gắn kết trong các kế hoạch cụ thể và có sự đánh giá, tác động lẫn nhau nhẳm hổ trợ vật chất và tinh thần cho nhân viên trong quá trình phát triển nghề nghiệp. Đào tạo nhân viên về cách thức truyền đạt tri thức có hiệu quả, dễ hiểu (thông qua các hoạt động hướng dẫn nâng cao khả năng diễn đạt, trình bày, thuyết trình...) từ đó giúp cho nhân viên cải thiện khả năng của mình để chia sẻ tri thức.

\section{KẾT LUẬN}


Các tiền đề và kết quả của ý định chia sẻ tri thức giữa các nhân viên trong các công ty du lịch được xác định trong nghiên cứu. Để đạt được mục tiêu này, dựa trên lý thuyết kỳ vọng và lý thuyết hành động hợp lý, một mô hình lý thuyết được phát triển, cùng với thảo luận về sự khác biệt tác động của các yếu tố động lực cá nhân bao gồm động lực bên trong (niềm vui) và động lực bên ngoài (sự có đi có lại và phần thưởng) đối với ý định của nhân viên trong việc chia sẻ tri thức và ảnh hưởng sau đó đến việc phát triển sản phẩm mới. Ngoài ra, bằng chứng thực nghiệm về mối quan hệ tích cực giữa phần thưởng và phát triển sản phẩm mới cũng được cung cấp. Những phát hiện của nghiên cứu cung cấp cho các nhà quản trị một khung tham chiếu để thiết kế các biện pháp can thiệp quản lý thúc đẩy động lực cá nhân nhằm tạo điều kiện thuận lợi cho việc chia sẻ tri thức và phát triển sản phẩm mới cho ngành $\mathrm{du}$ lịch.

Mặc dù nghiên cứu đã đạt được các mục tiêu đề ra, nhưng vẫn còn một số hạn chế và cần tiếp tục nghiên cứu trong tương lai. Trước hết, có thể mở rộng tổng thể nghiên cứu là các công ty du lịch đang hoạt động tại các tỉnh, thành phố khác để có cái nhìn toàn diện hơn. Ngoài ra, vì ý định hành vi còn phụ thuộc vào các yếu tố chuẩn mực chủ quan và kiểm soát hành vi nhận thức nên trong tương lai cần bổ sung các yếu tố này vào mô hình nghiên cứu nhằm làm tăng khả năng giải thích của mô hình.

\section{TÀI LIỆU THAM KHẢO}

Abernathy, W. J., \& Clark, K. B. (1985). Innovation: Mapping the winds of creative destruction. Research Policy, 14(1), 3-22. https://doi.org/10.1016/0048-7333(85)90021-6

Anderson, J. C., \& Gerbing, D. W. (1988). Structural Equation Modeling in Practice: A Review and Recommended Two-Step Approach. Psychological Bulletin, 103(3), 411-423. https://doi.org/10.1037/0033-2909.103.3.411

Bartol, K. M., \& Srivastava, A. (2002). Encouraging Knowledge Sharing: The Role of Organizational Reward Systems. Journal of Leadership and Organizational Studies, 9(1), 64-76. https://doi.org/10.1177/107179190200900105

Benner, M. J., \& Tushman, M. (2002). Process management and technological innovation: A longitudinal study of the photography and paint industries. Administrative Science Quarterly, 47(4), 676-707. https://doi.org/10.2307/3094913

Benner, M. J., \& Tushman, M. L. (2003). Exploitation, exploration, and process management: The productivity dilemma revisited. Academy of Management Review, 28(2), 238-256.
Blau, P. M. (1964). Exchange and Power in Social Life. John Wiley. https://doi.org/10.5465/amr.2003.9416096

Bock, G. W., Zmud, R. W., Kim, Y. G., \& Lee, J. N. (2005). Behavioural intention formation in knowledge sharing: Examining the roles of extrinsic motivators, social psychological forces, and organizational climate. MIS Quarterly, 29(1), 87-111. https://doi.org/10.2307/25148669

Bramwell, B. (1998). User satisfaction and product development in urban tourism. Tourism Management, 19(1), 35-47. https://doi.org/10.1016/S0261-5177(97)00091-5

Byrne, B.M. (2016). Structural Equation Modeling with Amos: Basic Concepts, Applications and Programming ( $3^{\text {rd }}$ ed.). Routledge. https://doi.org/10.4324/9781315757421

Cabrera, A., Collins, W. C., \& Salgado, J. F. (2006). Determinants of individual engagement in knowledge sharing. International Journal of Human Resource Management, 17(2), 245-264. https://doi.org/10.1080/09585190500404614

Calantone, R. J., Vickery, S. K., \& Dröge, C. (1995). Business Performance and Strategic New Product Development Activities: An Empirical Investigation. Journal of Product Innovation Management: An International Publication of the Product Development \& Management Association, 12(3), 214-223. https://doi.org/10.1111/1540-5885.1230214

Carbonell, P., \& Rodríguez-Escudero, A. I. (2016). The individual and joint effects of process control and process-based rewards on new product performance and job satisfaction. $B R Q$ Business Research Quarterly, 19(1), 26-39. https://doi.org/10.1016/j.brq.2015.04.001

Chang, S.C., \& Lee, M.S. (2008). The linkage between knowledge accumulation capability and organizational innovation. Journal of Knowledge Management, 12(1), 3-20. https://doi.org/10.1108/13673270810852359

Chang, T.J., Yeh, S.P., \& Yeh, I.J. (2007). The effects of joint reward systems in new product development. International Journal Manpower, 28(3/4), 276-297. https://doi.org/10.1108/01437720710755254

Cheng, M. Y., Ho, J. S. Y., \& Lau, P. M. (2009). Knowledge sharing in academic institutions: A study of multimedia university Malaysia. Electronic Journal of Knowledge Management, 7(3), 313-324.

Chennamaneni, A., Teng, J. T. C., \& Raja, M. K. (2012). A unified model of knowledge sharing behaviours: Theoretical development and empirical test. Behaviour \& Information Technology, 31(11), 1097-1115. https://doi.org/10.1080/0144929X.2011.624637 
Cho, M., Bonn, M. A., Giunipero, L., \& Jaggi, J. S. (2017). Contingent effects of close relationships with suppliers upon independent restaurant product development: A social capital perspective. International Journal of Hospitality Management, 67, 154-162. https://doi.org/10.1016/j.ijhm.2017.08.009

Choi, S. Y., Kang, Y. S., \& Lee, H. (2008). The effects of socio-technical enablers on knowledge sharing: an exploratory examination. Journal of Information Science, 34(5), 742-754. https://doi.org/10.1177/0165551507087710

Chow, W. S., \& Chan, L. S. (2008). Social network, social trust and shared goals in organizational knowledge sharing. Information \& Management, 45(7), 458-465. https://doi.org/10.1016/j.im.2008.06.007

Chowdhury, M., Prayag, G., Patwardhan, V., \& Kumar, N. (2020). The impact of social capital and knowledge sharing intention on restaurants' new product development. International Journal of Contemporary Hospitality Management., 32(10), 3271-3293. https://doi.org/10.1108/IJCHM-04-2020-0345

Danneels, E. (2002). The dynamics of product innovation and firm competences. Strategic Management Journal, 23(12), 1095-1121. https://doi.org/10.1002/smj.275

Davenport, T. H., \& Prusak, L. (1998). Working Knowledge: How Organizations Manage What They Know. Harvard Business School Press.

Deci, E. L., \& Ryan, R. M. (1987). The support of autonomy and the control of behavior. Journal of Personality and Social Psychology, 53(6), 10241037. https://doi.org/10.1037/00223514.53.6.1024

Deschamps, J.P., \& Nayak, P.R. (1995). Product Juggernauts: How Companies Mobilize to Generate a Stream of Market Winners. Boston, MA: Harvard Business School Press.

Fenwick, R., \& Olson, J. (1986). Support for worker participation: Attitudes among union and nonunion workers. American Sociological Review, 51(4), 505-522. https://doi.org/10.2307/2095584

Fornell, C., \& Larcker, D. F. (1981). Evaluating Structural Equation Models with Unobservable Variables and Measurement Error. Journal of Marketing Research, 18(1), 39-50. https://doi.org/10.1177/002224378101800104

Hair, J. F., Black, W. C., Babin, B. J., \& Anderson, R. E. (2014). Multivariate Data Analysis ( $7^{\text {th }}$ ed.). Pearson New International Edition.

Hallak, R., Assaker, G., O’Connor, P., \& Lee, C. (2018). Firm performance in the upscale restaurant sector: The effects of resilience, creative self-efficacy, innovation and industry experience. Journal of Retailing and Consumer
Services, 40, 229-240.

https://doi.org/10.1016/j.jretconser.2017.10.014

Hau, Y. S., Kim, B., Lee, H., \& Kim, Y. G. (2013).

The effects of individual motivations and social capital on employees' tacit and explicit knowledge sharing intentions. International Journal of Information Management, 33(2), 356-366. https://doi.org/10.1016/j.ijinfomgt.2012.10.009

He, Z. L., \& Wong, P. K. (2004). Exploration vs. Exploitation: An Empirical Test of the Ambidexterity Hypothesis. Organization Science, 15(4), 481-494. https://doi.org/10.1287/orsc.1040.0078

Hu, L. T., \& Bentler, P. M. (1999). Cutoff criteria for fit indexes in covariance structure analysis: Conventional criteria versus new alternatives. Structural Equation Modeling: A Multidisciplinary Journal, 6(1), 1-55. https://doi.org/10.1080/10705519909540118

Huang, Q., Davison, R. M., \& Gu, J. (2011). The impact of trust, guanxi orientation and face on the intention of Chinese employees and managers to engage in peer-to-peer tacit and explicit knowledge sharing. Information Systems Journal, 21(6), 557-577. https://doi.org/10.1111/j.1365-2575.2010.00361.x

Javaid, J., Soroya, S., \& Mahmood, K. (2020). Impact of personal and organizational factors on knowledge sharing attitude of university teachers in Pakistan. The Electronic Library, 38(2), 317336. https://doi.org/10.1108/EL-05-2019-0121

Kankanhalli, A., Tan, B. C., \& Wei, K. K. (2005). Contributing knowledge to electronic knowledge repositories: An empirical investigation. MIS Quarterly, 29(1), 113-143. https://doi.org/10.2307/25148670

Kline, R. B. (2015). Principles and Practice of Structural Equation Modeling ( $3^{\text {rd }}$ ed.). The Guilford Press.

Kollock, P. (1999). The economies of online cooperation: gifts and public goods in Cyberspace. In Smith, M., \& Kollock, P. (Eds), Communities in Cyberspace (pp. 220-239). Routledge.

Kunkel, J. G. (1997). Rewarding product development success. Research-Technology Management, 40(5), 29-31. https://doi.org/10.1080/08956308.1997.11671153

Lee, C., Hallak, R., \& Sardeshmukh, S. R. (2016). Innovation, entrepreneurship, and restaurant performance: A higher-order structural model. Tourism Management, 53, 215-228. https://doi.org/10.1016/j.tourman.2015.09.017

Levinthal, D. A., \& March, J. G. (1993). The Myopia of Learning. Strategic Management Journal, 14, 95-112. https://doi.org/10.1002/smj.4250141009

Liao, S. H., Chen, Y. J., \& Deng, M. Y. (2010). Mining customer knowledge for tourism new 
product development and customer relationship management. Expert Systems with Applications, 37(6), 4212-4223. https://doi.org/10.1016/j.eswa.2009.11.081

Lin, H. F. (2007). Effects of extrinsic and intrinsic motivation on employee knowledge sharing intentions. Journal of Information Science, 33(2), 135-149. https://doi.org/10.1177/0165551506068174

Martínez-Pérez, Á., García-Villaverde, P.M. and Elche, D. (2016). The mediating effect of ambidextrous knowledge strategy between social capital and innovation of cultural tourism clusters firms. International Journal of Contemporary Hospitality Management, 28(7), 1484-1507. https://doi.org/10.1108/IJCHM-08-2014-0405

McGrath, R. G. (2001). Exploratory learning, innovative capacity, and managerial oversight. Academy of Management Journal, 44(1), 118-131. https://doi.org/10.5465/3069340

Lê Văn Minh (2020, October 20). Phát triển sản phẩm du lịch cạnh tranh, đảm bảo cho du lịch Việt Nam phát triển bền vũng. http://itdr.org.vn/

Nakata, C., \& Sivakumar, K. (1996). National culture and new product development: An integrative review. Journal of Marketing, 60(1), 61-72. https://doi.org/10.1177/002224299606000106

Nguyễn Tấn Trung (2021, May 02). Giải pháp phát triển ngành Du lịch TP. Hồ Chí Minh. https://taichinhdoanhnghiep.net.vn/

Ogunmokun, O. A., Eluwole, K. K., Avci, T., Lasisi, T. T., \& Ikhide, J. E. (2020). Propensity to trust and knowledge sharing behavior: An evaluation of importance-performance analysis among Nigerian restaurant employees. Tourism Management Perspectives, 33(2020), 100590. https://doi.org/10.1016/j.tmp.2019.100590

Organ, D. W. (1988). Organizational citizenship behavior: The good soldier syndrome. Lexington Books.

Osterloh, M., \& Frey, B. S. (2000). Motivation, knowledge transfer, and organizational forms. Organization Science, 11(5), 538-550. https://doi.org/10.1287/orsc.11.5.538.15204

Raykov, M. (2014), 'Employer support for innovative work and employees' job satisfaction and job-related stress', Journal of Occupational Health, 56(4), 244-251. https://doi.org/10.1539/joh.12-0192-OA

Rothaermel, F. T., \& Deeds, D. L. (2004). Exploration and exploitation alliances in biotechnology: A system of new product development. Strategic Management Journal, 25(3), 201-221. https://doi.org/10.1002/smj.376
Sarin, S., \& Mahajan, V. (2001). The effect of reward structures on the performance of crossfunctional product development teams. Journal of Marketing, 65(2), 35-53. https://doi.org/10.1509/jmkg.65.2.35.18252

Scott, J. (2000). Rational choice theory. In G. Browning, A. Halcli, \& F. Webster (Eds.). Understanding contemporary society: Theories of the present (pp. 126-138). Sage Publications. https://doi.org/10.4135/9781446218310.n9

Sekaran, U., \& Bougie, R. (2016). Research Methods for Business: A Skill-Building Approach ( $7^{\text {th }}$ ed.). Wiley.

Stenmark, D. (2001). Levering tacit organizational knowledge. Journal of Management Information Systems, 17(3), 9-24. https://doi.org/10.1080/07421222.2000.11045655

Tamjidyamcholo, A., Baba, M. S. B., Tamjid, H., \& Gholipour, R. (2013). Information security Professional perceptions of knowledge-sharing intention under self-efficacy, trust, reciprocity, and shared-language. Computers \& Education, 68, 223-232. https://doi.org/10.1016/j.compedu.2013.05.010

Tang, Y.E. and Marinova, D. (2020). When less is more: the downside of customer knowledge sharing in new product development teams. Journal of the Academy of Marketing Science, 48(2), 288-307. https://doi.org/10.1007/s11747019-00646-w

Tushman, M. L., \& O'Reilly III, C. A. (1996). Ambidextrous organizations: Managing evolutionary and revolutionary change. California Management Review, 38(4), 8-29. https://doi.org/10.2307/41165852

Vroom, V.H. (1964). Work and Motivation. John Wiley.

Wang, Z., \& Wang, N. (2012). Knowledge sharing, innovation and firm performance. Expert Systems with Applications, 39(10), 8899-8908. https://doi.org/10.1016/j.eswa.2012.02.017

Wasko, M. M., \& Faraj, S. (2005). Why should I share? Examining social capital and knowledge contribution in electronic networks of practice. MIS Quarterly, 29(1), 35-57. https://doi.org/10.2307/25148667

Wei, Y. S., \& Atuahene-Gima, K. (2009). The moderating role of reward systems in the relationship between market orientation and new product performance in China. International Journal of Research in Marketing, 26(2), 89-96. https://doi.org/10.1016/j.ijresmar.2008.11.001

Witt, S. F., \& Witt, C. A. (1995). Forecasting tourism demand: A review of empirical research. International Journal of Forecasting, 11(3), 447-475. https://doi.org/10.1016/0169-2070(95)00591-7 